\title{
Self-Assembly Mechanism of Spiky Magnetoplasmonic Supraparticles
}

\author{
Hongjian Zhou, Jong-Pil Kim, Joong Hwan Bahng, Nicholas A. Kotov,* and Jaebeom Lee*
}

Concave nanoparticles (NPs) with complex angled and non-Platonic geometries have unique optical, magnetic, catalytic, and biological properties originating from the singularities of the electrical field in apexes and craters. Preparation of such particles with a uniform size/shape and core-shell morphology represents a significant challenge, largely because of the poor knowledge of their formation mechanism. Here, this challenge is addressed and a study of the mechanism of their formation is presented for a case of complex spiky morphologies that led us to the conclusion that NPs with concave geometries can be, in fact, supraparticles (SPs) produced via the self-assembly of smaller convex integrants. This mechanism is exemplified by the vivid case of spiky SPs formed via the attachment of small and faceted $\mathrm{Au}$ NPs on smooth Au-coated iron oxide $\left(\mathrm{Fe}_{3} \mathrm{O}_{4} @ \mathrm{Au}\right)$ seeds. The theoretical calculations of energies of primary interactions-electrostatic repulsion and van-der Waals repulsion, elaborated for this complex case-confirm experimental observation and the self-limiting mechanism of SP formation. Besides demonstrating the mechanistic aspects of synthesis of NPs with complex geometries, this work also uncovers a facile approach for preparation of concave magnetoplasmonic particles. When combined with a spiky geometry, such bi-functional magnetoplasmonic SPs can serve as a unique platform for optoelectronic devices and biomedical applications.

\section{Introduction}

Synthesis of noble-metal nanoparticles (NPs) with highly controlled non-spherical shapes represents challenging and rapidly

\section{H. Zhou}

Department of Nano Fusion Technology

Pusan National University

627-706, Republic of Korea

Dr. J.-P. Kim

High Technology Components \&

Materials Research Cente

Korean Basic Science Institute

Busan, 609-735, Republic of Korea

J. H. Bahng, Prof. N. A. Kotov

Department of Chemical Engineering

Materials Science, and Biomedical Engineering

University of Michigan, Ann Arbor

Michigan, 48109, USA

E-mail: kotov@umich.edu

Pro. J. Lee

Department of Nano-Integrated Cogno-mechatronics

Engineering (NICE)

Pusan National University

Busan, 609-735, Republic of Korea

E-mail: jaebeom@pusan.ac.kr

DOI: 10.1002/adfm.201302405 developing area of nanochemistry. A particularly interesting topic in this field is the synthesis and properties of NPs with concave nanoscale geometries. These NPs have distinct "spiky" shapes, with apexes that give rise to multiple optical, chemical, biological effects. NPs typically have Platonic geometries, which include tetrahedrons, cubes, hexahedrons, octahedrons, dodecahedrons, and icosahedrons, representing five regular tessellations of the sphere. Some examples of Archimedean and Johnson solids can also be found among NPs. ${ }^{[1-3]}$ From a geometrical perspective, all shapes mentioned above are convex. Concave NPs are much less common and, while known, ${ }^{[4-9]}$ their formation mechanism is still enigmatic. A large surface area, plasmonic hot spots, strong near-infrared absorbance, and special interactions with cells and cell components $^{[10-27]}$ differentiate concave spiky particles from NPs with spherical and/or other convex shapes. All of these properties have high practical relevance and, apart from the fundamental interest, make it possible to substantially advance NP applications in catalysis, photonics, electronics, plasmonics, sensing, biological labeling, imaging, and cancer therapy.

In general, the spiky particles are thermodynamically unstable and can potentially transform into spherical particles with time. ${ }^{[28]}$ The synthesis conditions for them were identified serendipitously, which does negate their importance or uniqueness but rather underlines the need to understand the underlying reasons for such growth pattern seeming deviating from thermodynamic control elaborated for "smooth" particles with Platonic shapes. While many papers do not describe the mechanism of formation of the spikes and focus primarily on the unusual morphology and optical properties of corresponding dispersions, ${ }^{[17,29,30]}$ the formation of the spiked or bristled particles is currently attributed to different tendency of the stabilizers exemplified by thioglycolic acid, ${ }^{[31]}$ poly(vinylpyrrolidone) $(\mathrm{PVP}),{ }^{[6]}$ or cetyltrimethylammonium bromide $(\mathrm{CTAB}),{ }^{[7]}$ to absorb on diverse crystal faces. ${ }^{[6,8]}$ The pivotal role of surface defects on NP seeds increasing in numbers under rapid growth conditions was also suggested as potential reason for the growth of spikes. ${ }^{[7]}$

These explanations involving the thermodynamically controlled variability of stabilizer density and kinetically controlled density of defects as well as the combination thereof, however, 
are difficult to accept because the spikes grow without an apparent symmetrical relation between them. Also, the growth of the spikes occurs on seeds coated with different surfactants and displaying a variety of atomic faces including smooth surfaces of fairly large rods and beads. ${ }^{[32]}$ The view of surface defects as the primary factor in production of spiky particles is difficult to rationalize in the view of the high crystallinity of the resulting particles.

Some of these controversies originate from the atom-byatom model for the growth of nanoparticle that start with seeds of critical size and grow according to the kinetics of ion/atom attachment to different crystal faces. ${ }^{[35,36]}$ However, this model does not always determine the growth of the particles and, in particularly their shapes. ${ }^{[27,37,38]}$ One should also notice that rapid growth conditions are common requirement for a variety of nanocolloids where the growth of spiky NPs were demonstrated. ${ }^{[3,34]}$ Both of these observations led us to consider an alternative mechanism for the formation of spiky particles and other complex non-Platonic shapes. Recently, the concept of a self-limiting process was suggested as a way of growing monodispersed supraparticles (SPs), mimicking the supramolecular assemblies that occur in proteins, such as in viral capsids. ${ }^{[39]}$ The size of SPs is quite similar to the dimensions of spiky particles made so far and their surface also display similar roughness. ${ }^{[39]}$ The yield of SPs approached $100 \%$ is also similar to the yields observed for some spiky particles. ${ }^{[6]}$ Such similarities are unlikely (although possible) to be coincidental and in this work we decided to investigate the growth of spiky NPs having from the perspective of potential SP involvement in their formation. We demonstrate here successful synthesis of spiky coreshell particles that are, in fact, self-assembled SPs made from $\mathrm{Au}$ and $\mathrm{Fe}_{3} \mathrm{O}_{4}$ NPs (Scheme 1). We also present experimental and theoretical data supporting the idea that spiky shapes are produced not due local kinetic or structural in homogeneities but due to self-assembly of individual NPs generated in-situ into larger structures. We believe that these findings will help to understanding the mechanism(s) governing the formation of spiky particles better and can open the door to synthesis of even more complex concave non-Platonic shapes. As such, the careful evaluation of the mechanistic aspects of "spiky" synthesis, SPs made from $\mathrm{Au}$ and $\mathrm{Fe}_{3} \mathrm{O}_{4}$ NPs represent the first example of nanoscale convex particles combining two inorganic nanomaterials: magnetic and plasmonic. Consideration of SP self-assembly route makes possible to form SPs ${ }^{[30]}$ with spiky shape, tunable diameters (ca. 95-185 nm), plasmonic absorption in 600-700 $\mathrm{nm}$ region and strong magnetization.

\section{Results and Discussion}

\subsection{Synthesis and Structure}

We decided to approach the problem of their synthesis from the perspective of the assembly of NPs on pre-made nanoscale cores considering that the attachment of the additional nanoscale "building blocks" will be controlled by the balance of attractive and repulsive interactions as was demonstrated in a previous publication. ${ }^{39]}$ This approach is consistent with the previously reported protocols for synthesis of spiky particle under different conditions. ${ }^{[7,30-32]}$ One substantial difference is that the resulting SPs could correspond to the state of local thermodynamic minimum, which makes it possible to accurately control their diameter. Alternatively, the availability of the total amount of the additional constituent NPs can also control their size. The self-assembly approach allows one to mix-and-match different types of NPs starting with one type and making a shell around it from another type, which is an additional advantage that let to our interest in this process.

We started with citrate-stabilized $\mathrm{Fe}_{3} \mathrm{O}_{4}$ NPs made by conventional approach. A transmission electron microscopic (TEM) images of the resulting NPs is shown in Figure 1a. These initial $\mathrm{Fe}_{3} \mathrm{O}_{4}$ NPs were almost spherical with average size $\sim 10 \mathrm{~nm}$, as seen in the high magnification TEM micrograph in Figure S1 and the particle size distribution in Figure S2-A. After fabricating the magnetic cores, we coated them with the first layer of $\mathrm{Au}$ to produce spherical $\mathrm{Fe}_{3} \mathrm{O}_{4} @ \mathrm{Au}$ core-shell particles with a smooth surface (Figure 1b). These particles served as seeds for assembling the SPs. The synthesis of smooth, spherical $\mathrm{Fe}_{3} \mathrm{O}_{4} @$ $\mathrm{Au}$ core-shell particles was accomplished by adding $\mathrm{Fe}_{3} \mathrm{O}_{4} \mathrm{NPs}$ to boiling $\mathrm{HAuCl}_{4}$ in the presence of citrate as a stabilizer and a reducing agent (see Experimental Section). ${ }^{[58]}$ The resulting fairly monodispersed $\mathrm{Fe}_{3} \mathrm{O}_{4} @$ Au core-shell particles had purple color associated with the optical properties of the smooth shells of $\mathrm{Au}$ (Figure 1b) (average size is $25 \pm 2.4 \mathrm{~nm}$, Figure S2-B). ${ }^{[59]}$

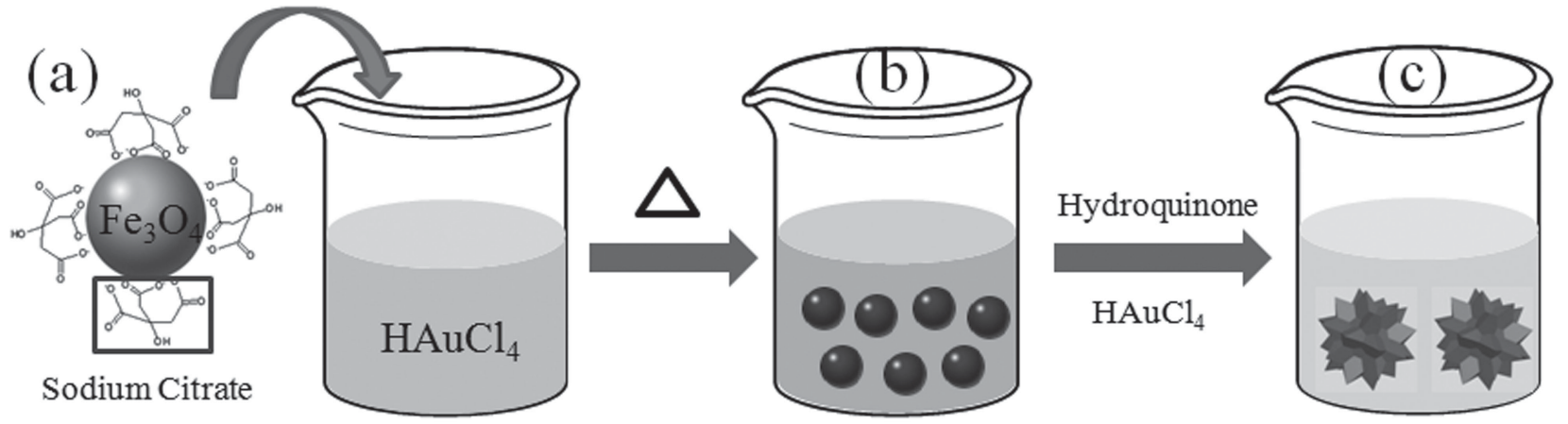

Scheme 1. Schematic for preparation of spiky Au-coated magnetic SPs: a) synthesis of spherical Fe $\mathrm{O}_{4} \mathrm{NPs}$; b) deposition of a Au Fe $\mathrm{O}_{4} \mathrm{NP}$ layer to produce spherical $\mathrm{Fe}_{3} \mathrm{O}_{4} @ \mathrm{Au} \mathrm{NPs}$; and c) assembly of in situ-generated active Au NPs on spherical Fe $\mathrm{O}_{4} @ A$ A $\mathrm{NPs}$ to produce spiky SPs. (NP sizes are not to scale.) 

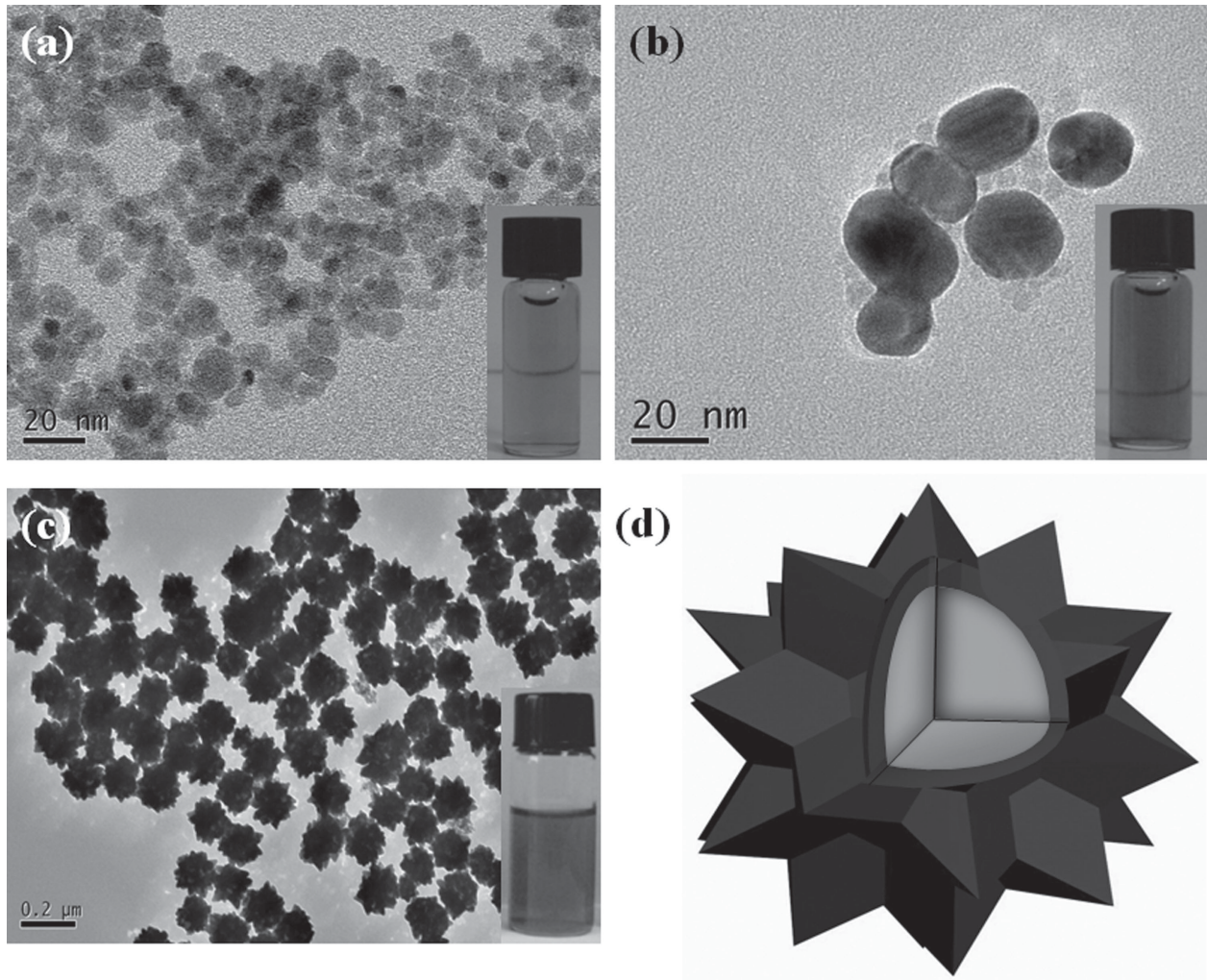

Figure 1. TEM images of a) $\mathrm{Fe}_{3} \mathrm{O}_{4}$ nanoparticles; b) nearly spherical $\mathrm{Fe}_{3} \mathrm{O}_{4} @$ @u core-shell particles with smooth layer of gold; c) spiky SPs made by self-assembly of in situ-generated Au NPs on $\mathrm{Fe}_{3} \mathrm{O}_{4} @$ @u core-shell particles; and d) a 3D schematic drawing of spiky SPs. Insets in each TEM image show the photograph of corresponding aqueous dispersions.

Small $\mathrm{Fe}_{3} \mathrm{O}_{4} \mathrm{NPs}(\sim 5 \mathrm{~nm})$ not coated by Au shells were sometimes attached on the surface of larger $\mathrm{Fe}_{3} \mathrm{O}_{4} @ \mathrm{Au}$ particles. The thickness of the Au shell is estimated to be around $7.5 \pm 1.2 \mathrm{~nm}$ according to the TEM images in Figure 1a,b.

Combining scanning transmission electron microscopy (STEM) with energy-dispersive X-ray spectroscopy (EDXS) and scanning the NPs with 1.0-nm diameter beam, it was possible to distinguish the component elements, including $\mathrm{Au}, \mathrm{Fe}$ and $\mathrm{O}$ (Figure S3). In the micrographs, $\mathrm{Fe}_{3} \mathrm{O}_{4}$ NPs coated with $\mathrm{Au}$ appear much darker than the uncoated $\mathrm{Fe}_{3} \mathrm{O}_{4}$ NPs because $\mathrm{Au}$ is more electron-dense than iron oxide. The line mapping of the selected NPs indicates the inclusion of a Fe core and a Au shell as a single $\mathrm{Fe}_{3} \mathrm{O}_{4} @ \mathrm{Au}$ nanostructure. ${ }^{[60,61]}$ The relative ratio of $\mathrm{Au}$ to Fe in the selected NP was found to be 16:1 (Figure S3-B). The EDXS maps show that $\mathrm{Fe}, \mathrm{Au}$ and $\mathrm{O}$ are present in the same NPs, which is consistent with the core-shell morphology.

Instead of citrate, hydroquinone was used as reducing agent because the redox potential of hydroquinone, $-0.699 \mathrm{~V}$ versus a normal hydrogen electrode (NHE), Hydroquinone $\Leftrightarrow 2 H^{+}+2 e+$ Benzoquinone, ${ }^{[58,62]}$ is substantially more negative than the redox potential of citrate, $-0.5 \mathrm{~V}$ versus NHE, Citric acid $\Leftrightarrow \mathrm{CO}_{2}+\mathrm{H}_{2} \mathrm{O}+2 e+$ Acetonedicarboxplic acid $[63,64]$ This difference in reduction potential resulted in the fast formation $^{[65]}$ of $\mathrm{Au}$ NPs when using hydroquinone. Although we expected these $\mathrm{Au}$ NPs to agglomerate with the premade smooth, spherical $\mathrm{Fe}_{3} \mathrm{O}_{4} @ \mathrm{Au}$ core-shell particles serving as seeds, these weakly stabilized NPs are expected to promote attractive interactions owing to low zeta potential value $(\zeta=-9.77 \mathrm{mV})$ reported previously. ${ }^{[66]}$

The TEM images (Figure 1) show that the spiky morphology indeed gradually developed. The number of branches in the spiky $\mathrm{SP}_{\mathrm{S}}$ was approximately 25-30 per particle. The diameter of the spiky SPs was ca. $185 \mathrm{~nm}$, resulting in distinct green dispersions (Figure 1c). The size distribution curve of the spiky SPs shows an average diameter of approximately $190 \mathrm{~nm}$ (Figure S2-C, Supporting Information). There were no significant absorption features in the visible region of the electromagnetic spectrum for dispersions of the starting $\mathrm{Fe}_{3} \mathrm{O}_{4} \mathrm{NPs}$. The surface plasmon peaks for the spiky $\mathrm{Fe}_{3} \mathrm{O}_{4} @ \mathrm{Au}$ core-shell SPs appeared in the range 470-800 $\mathrm{nm}$ and differed markedly from the citrate-stabilized Au NPs in water, which exhibited a surface plasmon peak at $520 \mathrm{~nm} .{ }^{[70]}$ The AFM and SEM images of the smooth, spherical $\mathrm{Fe}_{3} \mathrm{O}_{4} @ \mathrm{Au}$ seed NPs and spiky SPs is shown in Figure S4. Comparing Figure S4, we can clearly see the difference in the morphology between these two core-shell NPs. The spiky SPs show a rougher surface than the spherical NPs because of the presence of tips.

\subsection{Mechanism of Formation}

To support the hypothesis that the spiky particles observed in this synthetic process are, in fact, SPs formed as a result of 
self-assembly and $\mathrm{Fe}_{3} \mathrm{O}_{4} @ \mathrm{Au}$ core-shell particles are required to initiate the process, we evaluated the interaction potential at 3 chronological stages of assembly; interaction between hydroquinone reduced $\mathrm{Au} \mathrm{NPs}$ and $\mathrm{Fe}_{3} \mathrm{O}_{4} @ \mathrm{Au}$ core-shell (initial stage, stage i), intermediate SPs (growth stage, stage g) and fully grown SPs (self-termination stage, stage f). For each stage, geometrical assumptions and physical specifications are described in the Supplementary Information. The van der Waals (VdW) interaction energies between two dissimilar spheres are evaluated with the following equation. ${ }^{[67]}$

$V v d w=-\frac{A_{132}}{6 x} \frac{\left(R_{1} R_{2}\right)}{\left(R_{1}+R_{2}\right)}$

where $A_{132}$ is the Hamaker's constant of material 1 and 2 across medium $3, R_{\mathrm{i}}$ is the radius and $x$ is the closest distance between the two spheres. Here, 1, 2 and 3 are $\mathrm{Au}, \mathrm{Fe}_{3} \mathrm{O}_{4}$, and water respectively. The double layer electrical energies between two dissimilar spheres is represented from the following equation. ${ }^{[68]}$

$$
\begin{aligned}
V_{D L}= & \frac{\pi \varepsilon_{0} \varepsilon_{r} R_{1} R_{2}}{\left(R_{1}+R_{2}\right)}\left(\zeta_{1}^{2}+\zeta_{2}^{2}\right) \\
& \times\left\{\frac{2 \zeta_{1} \zeta_{2}}{\zeta_{1}^{2}+\zeta_{2}^{2}} \ln \left(\frac{1+e^{-\kappa x}}{1-e^{-\kappa x}}\right)+\ln \left(1-e^{-2 \kappa x}\right)\right\}
\end{aligned}
$$

where $\varepsilon_{0}$ is the permittivity of vacuum, $\varepsilon_{\mathrm{r}}$ is the dielectric constant of water, $\zeta_{\mathrm{i}}$ is the zeta potential. Practical Debye Length, $\kappa^{-1} \approx 100 \mathrm{~nm},{ }^{[69]}$ is used to account for dissolved $\mathrm{CO}_{2}$ that converts to carbonic acid. The total interaction potential is given by

$$
V_{D L V O}=V_{v d w}+V_{D L}
$$

The analysis shows that the interaction at stage $i$ has the most attractive potential, Figure 2a, and energetically accounts for mechanism that initiates the self-assembly. Also note that the direct assembly of Au NPs produced by the hydroquinone reaction of the surface of bare $\mathrm{Fe}_{3} \mathrm{O}_{4}$ NPs failed. The $\mathrm{Au}$ is known to have one of the highest Hamaker's constant and its smooth shell on $\mathrm{Fe}_{3} \mathrm{O}_{4}$ was necessary to strengthen the VdW interaction energies and overcome the electrostatic repulsion because of the similarity of charges on the citrate-stabilized NPs and newly formed $\mathrm{Au}$ NPs reduced by hydroquinone. Figure $2 \mathrm{~b}$ shows that the attractive potential is indeed superior with the presence of $\mathrm{Au}$ shell.

The formation of spiky SPs by attaching free NPs made extraneously in solution is confirmed by presence of facets, seen in the HR-TEM images in Figure 3. The individual constituent NPs retained in the assembled structure were monocrystalline. A filtered lattice image (Figure 3b, take from the square in Figure 3a) revealed that fringes are caused by the reciprocal lattice points only (branch of the spiky SPs). Its fast Fourier transform (FTT) pattern is shown in the inset of Figure 3b. This high-resolution image of Au spikes clearly shows the uniform lattice structure of a single crystal. The fringe spacing was measured to be $0.196 \mathrm{~nm}$, which corresponds to the spacing between the (200) planes of the face-centered cubic Au (0.204 nm) (JCPDS card no. 04-0784). At the same time, the selected area electron diffraction (SAED) pattern of all the spiky SPs revealed polycrystallinity, as evidenced by the gradual epitaxial atom-by-atom growth of the $\mathrm{Au}$ spikes on the previously formed smooth $\mathrm{Fe}_{3} \mathrm{O}_{4} @ \mathrm{Au}$ NPs (Figure 3c). The SAED pattern is superposition of $\mathrm{Au}$ and $\mathrm{Fe}_{3} \mathrm{O}_{4}$ lattices, showing five distinguishable planes of (111), (200), (220), (311), (222) from $\mathrm{Au}$ and one distinguishable (311) plane from $\mathrm{Fe}_{3} \mathrm{O}_{4}$. Other planes overlap with the Au planes. ${ }^{[71]}$

The XRD diffraction data also confirmed that the spiky SPS were polycrystalline. The XRD peaks from the SPs fitted well to those of the $\mathrm{Au}$ and $\mathrm{Fe}_{3} \mathrm{O}_{4}$ bulk phases (Figure 3d). The $\mathrm{Au}$ diffraction peaks matched the reflections of the (111), (200), (220), (311), and (222) planes. The $\mathrm{Fe}_{3} \mathrm{O}_{4}$ diffraction peaks can be ascribed to the (220), (311), and (440) planes. ${ }^{[72,73]}$ The
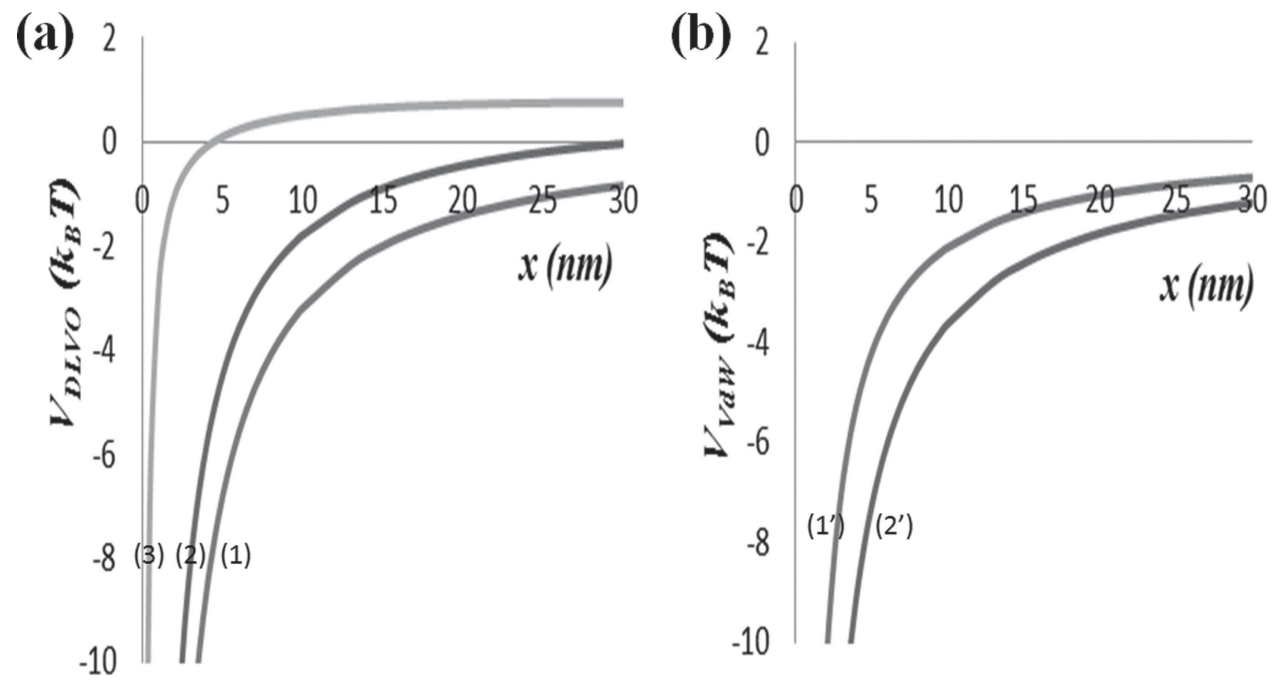

Figure 2. a) $V_{D L v o}$ through the progressive stages; stage $i$ (line (1)), stage $g$ (line (2)), stage $f$ (line (3)). The initial core-shell stage has the most attractive potential. The self-termination stage is explained via the repulsive potential between the SPs and the hydroquinone reduced Au NPs. b) $V_{V d w}$ at stage 0 (line ( $\left.1^{\prime}\right)$ ) and stage $i$ (line(2')). The stage 0 represents the interaction between bare $\mathrm{Fe}_{3} \mathrm{O}_{4} \mathrm{NPs}$ and hydroquinone reduced Au NPs. The VdW attraction is enhanced with the presence of Au shell around the $\mathrm{Fe}_{3} \mathrm{O}_{4} \mathrm{NP}$. 

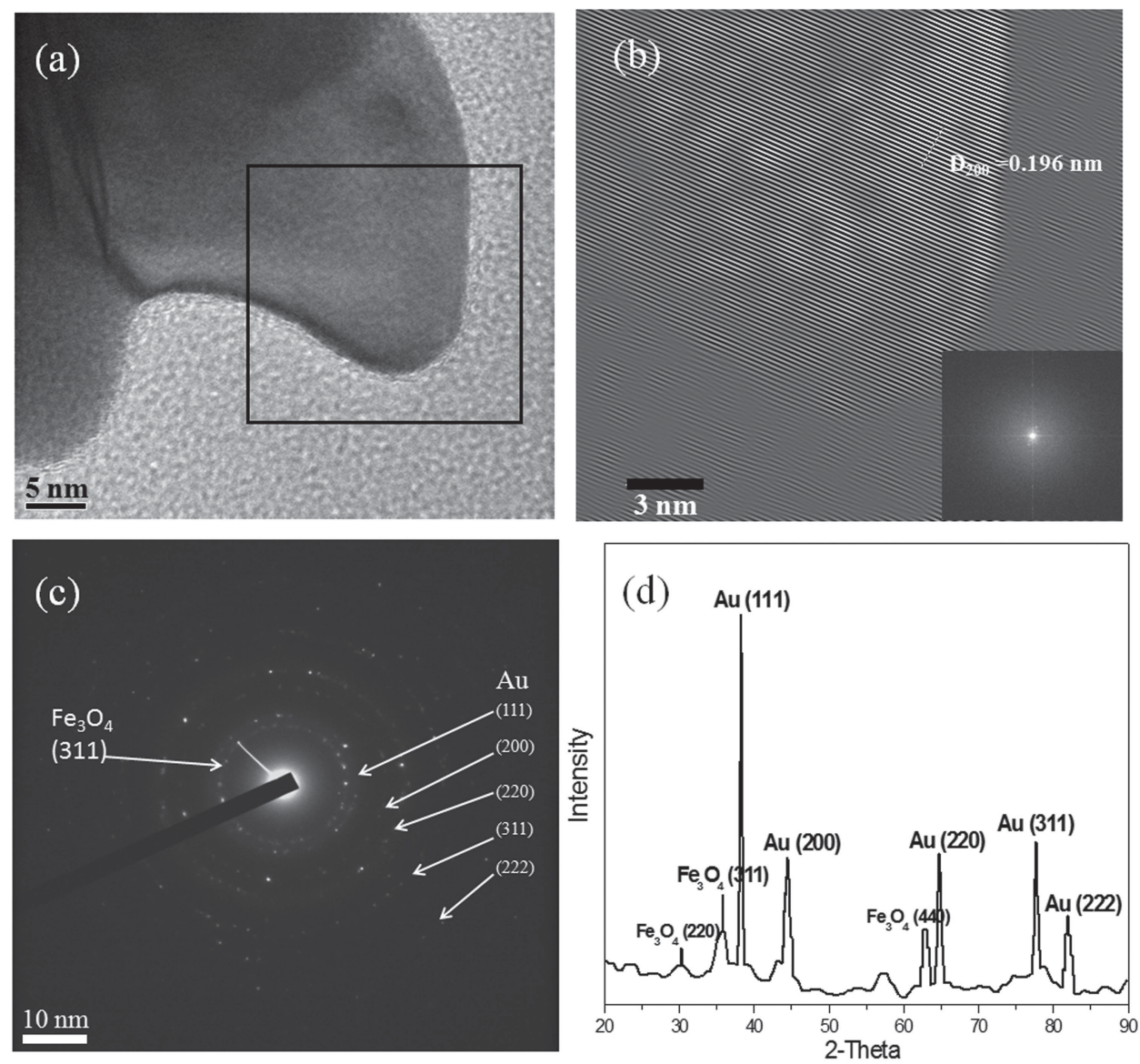

Figure 3. a) HR-TEM image of one branch of spiky SPs; b) filtered lattice image reveals fringes due only to the reciprocal lattice points of black square in (a) and the FFT pattern of selected area within (a); c) selected area electron diffraction (SAED) pattern of spiky SPs; and d) XRD pattern of spiky SPs.

assembly route for the formation of the spiky SPs was further substantiated by the negative control experiment: spiky SPs were absent in the reaction media when no strong reducing agent-hydroquinone-was present; however, the reduction of $\mathrm{HAuCl}_{4}$ was still initiated in the presence of smooth $\mathrm{Fe}_{3} \mathrm{O}_{4} @$ $\mathrm{Au}$ core-shell particles. There, when atom-by-atom growth mode on the existing Au shell was possible but individual constituent NPs in solution were absent (Figure S5, Supporting Information), ${ }^{[58]}$ the spiky morphology does not appear. For the additional confirmation of the self-assembly mechanism, we observe the gradual time-dependent size increase of the spiky SP growth by TEM (Figure S6, Supporting Information), indicating that the length of the spikes (ca. $10 \mathrm{~nm}$ ) was approximately the same at the initial and final stages of SP formation, which corresponds very well to the size of individual Au NPs generated in solution.

\subsection{Deviations from the Expected Self-Assembly Mechanism and its Synthetic Implications}

We anticipated that the agglomeration/assembly of the in situgenerated $\mathrm{Au}$ NPs on $\mathrm{Fe}_{3} \mathrm{O}_{4} @ \mathrm{Au}$ core-shell particles would have the same self-limiting kinetics previously observed. ${ }^{[37,38,74]}$
In other words, the size of the SPs would reach a critical point when the electrostatic repulsion between the SPs and the free NPs in solution would be the dominating force. This is attributed to decrease in the effective Hamaker's constant leading to reduction in the VdW interaction energies between the SPs and hydroquinone reduced $\mathrm{Au}$ NPs (Figure 2a). However, their formation mechanism did not confirm these expectations, and we found important differences with the previously observed assembly process. We did not see any evidence of gaps between the newly attached $\mathrm{Au}$ NPs or between them and the original smooth $\mathrm{Fe}_{3} \mathrm{O}_{4} @ \mathrm{Au}$ core. However, these gaps were clearly visible in the previous examples of SPs made from semiconductor NPs, as well as in SPs made from the combination of a semiconductor and Au NPs. ${ }^{[39]}$ We attribute this difference to (a) the dynamic nature of citrate as a stabilizing agent and (b) the presence of high-energy crystalline facets in the newly formed NPs. As such, the crystalline facet corresponding to the high-energy (200) plane accounted for the strong signal in the HRTEM and electron diffractogram. The current results represent a new case in which SPs transform after assembling into a continuous structural unit. The integration of the lattices (although not necessarily epitaxial) of the pre-made cores with smooth Au shells and newly attached, fairly large NPs could be compared to the analogous process observed in the assembly of PbS NPs. ${ }^{[37]}$ 

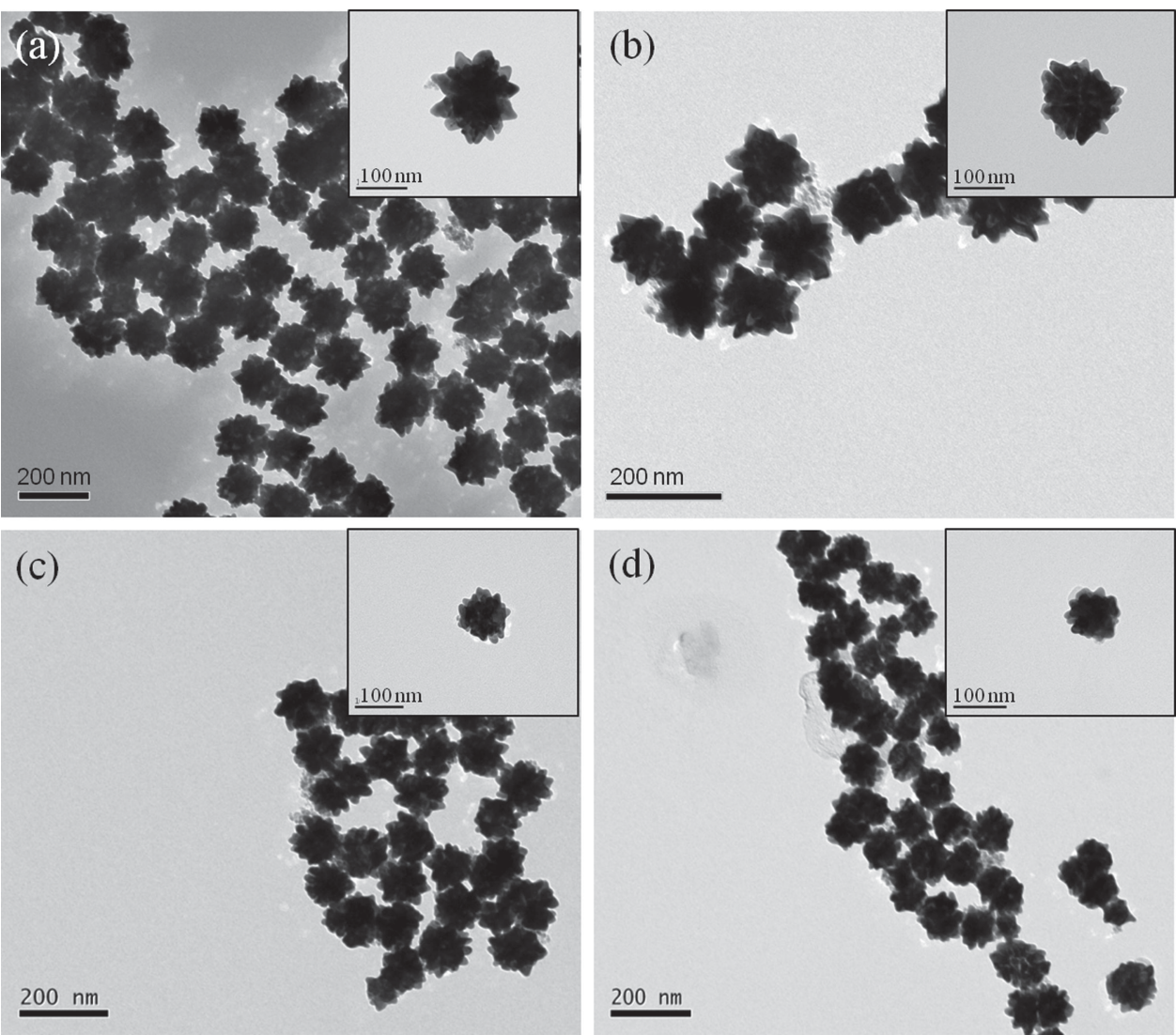

Figure 4. TEM images of spiky SPs assembled in the presence of different amounts of smooth $\mathrm{Fe}_{3} \mathrm{O}_{4} @ \mathrm{Au}$ core-shell particles: (a) $4.5 \mathrm{nM}$, (b) $8.9 \mathrm{nM}$, (c) $13.2 \mathrm{nM}$, and (d) $17.5 \mathrm{nM}$. Insets show magnified images of corresponding individual SPs. [Volume of smooth $\mathrm{Fe}_{3} \mathrm{O}_{4} @ \mathrm{Au}$ seeds increased from 100 to $400 \mu \mathrm{L}$ in $100 \mu \mathrm{L}$ increments for spectra (a)-(d).]

The transformation from the SP with gaps to the assembly without gaps let us to rethink the strategy for the control of the SP diameters. Although it could be beneficial for their optical and/or electrical properties, lattice-to-lattice connectivity between the NPs forming the SPs diminishes their ability to dis-assemble as their overall charge increases, which, therefore, eliminates the local thermodynamic minimum corresponding to the equal energy of attachment of NPs and detachment of previously assembled NPs. However, it leaves the possibility of controlling the SP diameter by limiting the pool of additional $\mathrm{Au}$ NPs available for assembly. For instance, it could be done by varying the ratio of smooth $\mathrm{Fe}_{3} \mathrm{O}_{4} @ \mathrm{Au}$ NPs to the total number of new Au NP being reduced by hydroquinone. Indeed, as the amount of smooth $\mathrm{Fe}_{3} \mathrm{O}_{4} @ \mathrm{Au}$ seeds increased from 100 to $500 \mu \mathrm{L}$ while keeping the quantities of $\mathrm{HAuCl}_{4}$ and hydroquinone fixed, we were able to decrease the average diameter of the spiky SPs from $175 \pm 9.1 \mathrm{~nm}$ to $95 \pm 6.3 \mathrm{~nm}$ (Figure 4). Correspondingly, the color of the solution shifted from green to blue and the maximum wavelength of absorption in the UV-visible absorption spectra changed from 670 to $600 \mathrm{~nm}$ (Figure 5b). Having fewer $\mathrm{Au}$ NPs available for attachment to the Au surface, led to the growth of each SP to large diameters, which is similar to the growth mechanism of individual $\mathrm{NPs},{ }^{[58,70]}$ and thus had to follow the same growth equations. ${ }^{[37]}$ A qualitatively similar effect could be obtained by using different concentrations of hydroquinone. The concentration of the reducing agent limited the number of constituent Au NPs formed, and, therefore, limited the size of the resulting SPs while maintaining the uniformity of their diameters and overall morphology (Figure 6). As the amount of the $30 \mathrm{mM}$ hydroquinone solution increased from 125 to $1000 \mu \mathrm{L}$, the diameter of the SPs increased from $105 \pm 5.9 \mathrm{~nm}$ to $185 \pm 11.4 \mathrm{~nm}$. The length and the number of spikes (Figures 6b,c,d) increased as the plasmon absorption of the NPs shifted from 605 to $650 \mathrm{~nm}$ (Figure 6a).

\subsection{Magnetoplasmonic Properties}

The synthesis of spiky shapes of magneto-plasmonic particles is particularly attractive for obtaining large optical cross sections for NIR photons necessary for applications in biomedical imaging and drug delivery ${ }^{[40,41]}$ because of the transparency of biological tissues at these wavelengths. ${ }^{[42]}$ Concomitantly, $\mathrm{Fe}_{3} \mathrm{O}_{4}$ NPs are useful as $T_{2}$-weighted contrast agents in magnetic resonance imaging, magnetofection, and cell sorting ${ }^{[43,44]}$ including detection of rare cells, owing to their unique magnetic properties and biocompatibility. Combining these magnetic properties with spiky plasmonic shells of Au will enable better cancer 

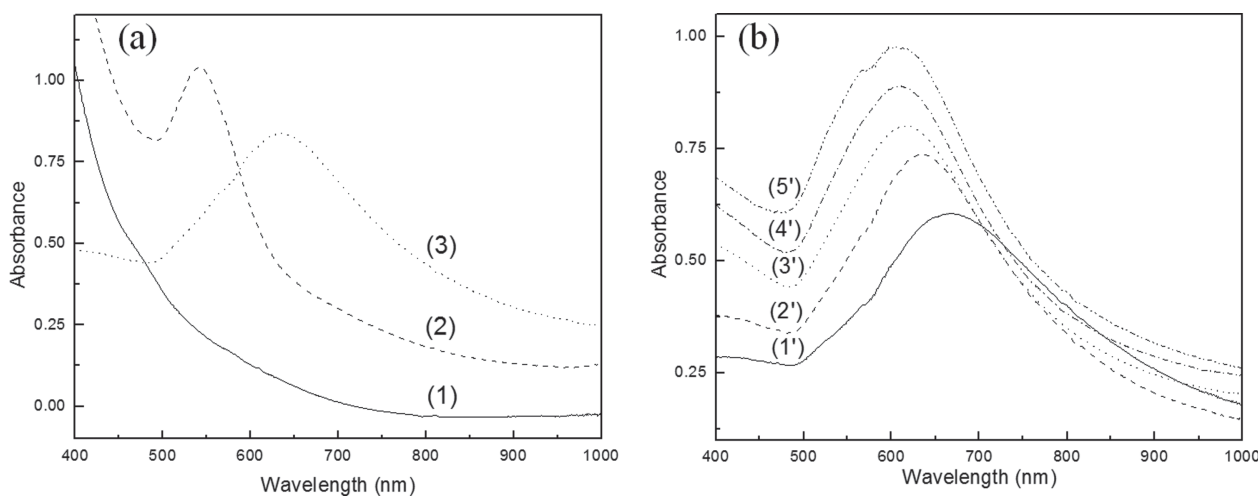

Figure 5. a) UV-visible spectra of (1) aqueous dispersions with $\mathrm{Fe}_{3} \mathrm{O}_{4} \mathrm{NPs}$, (2) nearly spherical smooth $\mathrm{Fe}_{3} \mathrm{O}_{4} @ \mathrm{Au}$ core-shell particles, and (3) spiky SPs. b) UV-visible absorption spectra of spiky SPs solutions assembled in the presence of different amounts of smooth $\mathrm{Fe}_{3} \mathrm{O}_{4} @ \mathrm{Au}_{\mathrm{u}}$ core-shell particles serving as seeds for the assembly of SPs: (1') 4.5 nM; (2') 8.9 nM; (3') 13.2 nM; (4') 17.5 nM; and (5') 21.7 nM. [Volume of smooth Fe ${ }_{3} \mathrm{O}_{4} @ A u$ seeds increased from 100 to $500 \mu \mathrm{L}$ in $100 \mu \mathrm{L}$ increments for spectra $\left(1^{\prime}\right)$ to $\left(5^{\prime}\right)$.]

diagnosis/therapy, ${ }^{[45]}$ imaging, ${ }^{[46,47]}$ DNA analysis, ${ }^{[48,49]}$ and drug delivery. ${ }^{[50,51]}$ In addition, the dielectric properties and chemical stability of nanostructures made of spiky $\mathrm{Fe}_{3} \mathrm{O}_{4}-\mathrm{Au}$ SPs makes them ideal substrates for the study of well-defined plasmon resonances within the visible and NIR spectral ranges with high electromagnetic fields in the vicinity of NP apexes. The spiky $\mathrm{Fe}_{3} \mathrm{O}_{4}-\mathrm{Au}$ nanostructures can be used for surface-enhanced Raman scattering (SERS), ${ }^{[52,53]}$ heterogeneous catalysts, and DNA colorimetric sensing devices. ${ }^{[41,54]}$ A strong SERS activity can be detected with intensity over $10^{7}$ and a relatively high reproducibility. ${ }^{[55,56]}$ In addition, the spiky-like structure leads to large SPR shift from 500 to $800 \mathrm{~nm}$ and tunable SPR enhancement light scattering and absorption, making them novel and high effective contrast agents for in vivo cancer diagnosis and therapy. Moreover, the spiky metallic nanoparticles, with increased surface area-to volume ratio, a larger number of surface defects, and tips with selected crystallinity, display excellent catalytic properties compare with spherical particles. ${ }^{[57]}$

The optical response of the spiky SPs is dominated by the plasmon mode associated with the gold tips and can be rationalized in terms of plasmon hybridization: a concept originally developed for nanoshells. ${ }^{[75,76]}$ The plasmons of spiky SPs arise due to the hybridization of the plasmons supported by the inner radius (gold cavity), the outer radius of the shell layer (spiky gold surface) and lower frequency plasmon oscillations at the tips. This hybridization results in a complex, multipeaked optical spectrum where the thickness of the intermetallic dielectric layer controls the mode coupling, and the tip aperture angle and length effects can induce red-shifting of the collective plasmon modes. The tips are also responsible for an increase in the extinction cross section (a fourfold increase with respect to the individual tip plasmons).

Thus, the spiky SPs showed that the plasmon bands were red-shifted with respect to those for spheres $\mathrm{Fe}_{3} \mathrm{O}_{4} @ \mathrm{Au}$ coreshell particles. They also showed very high electromagnetic fields localized at each tip. From the UV-visible absorption spectra of spiky SPs (Figures 5 and 6a), we can clearly see that spiky SPs display three distinct plasmonic features: an intense band typically centered around 600-670 nm and two weaker shoulders located at ca. 566 and $800 \mathrm{~nm}$. It might is expected that the tip aperture angle and length strongly were found to strongly affect the energy of the plasmon hybridization mode at the tip, whereas the core size has a milder influence and the number of tips modulates the intensity of plasmonic tip modes.

The measurement of the magnetic properties of the spherical $\mathrm{Fe}_{3} \mathrm{O}_{4} @ \mathrm{Au}$ NPs and spiky $\mathrm{Fe}_{3} \mathrm{O}_{4} @ \mathrm{Au}$ SPs using the SQUID technique allowed us to assess the saturation magnetization, coercivity, susceptibility, and blocking temperature of the NPs. Figure 7a shows the spherical $\mathrm{Fe}_{3} \mathrm{O}_{4} @ \mathrm{Au}$ NPs and spiky $\mathrm{Fe}_{3} \mathrm{O}_{4} @ \mathrm{Au}$ SPs hysteresis loops measured at room temperature. The saturation magnetization $(\mathrm{Ms})$ of spherical $\mathrm{Fe}_{3} \mathrm{O}_{4} @$ $\mathrm{Au}$ NPs was $16.2 \mathrm{emu} \mathrm{g}^{-1}$ at room temperature. Like the spherical $\mathrm{Fe}_{3} \mathrm{O}_{4} @ \mathrm{Au}$ NPs, spiky $\mathrm{Fe}_{3} \mathrm{O}_{4} @ \mathrm{Au}$ SPs were nearly paramagnetic at room temperature, and had an Ms of $5.2 \mathrm{emu} \mathrm{g}^{-1}$. This suggests that the Ms of spherical $\mathrm{Fe}_{3} \mathrm{O}_{4} @ \mathrm{Au}$ NPs drops slightly when the surface is coated with $\mathrm{Au}$. It also indicates that exchange interactions with the ligand or outer layers, like the gold coating, at the surface did not affect the movement of the inner $\mathrm{Fe}_{3} \mathrm{O}_{4}$ NPs too much. ${ }^{[77]}$ Moreover, the spherical $\mathrm{Fe}_{3} \mathrm{O}_{4} @ \mathrm{Au}$ NPs and spiky $\mathrm{Fe}_{3} \mathrm{O}_{4} @ \mathrm{Au}$ SPs that were separated using a magnet are shown in inset (1) and (2) of Figure 7b. These results show that the $\mathrm{Fe}_{3} \mathrm{O}_{4} @ \mathrm{Au}$ NPs were separable using high-gradient magnetic filtration. After magnetic separation, the $\mathrm{Fe}_{3} \mathrm{O}_{4} @ \mathrm{Au}$ NPs were still well dispersed in aqueous solutions. The spiky $\mathrm{Fe}_{3} \mathrm{O}_{4} @ \mathrm{Au}$ SPs had a surface plasmon peak at the high wavelength of $640 \mathrm{~nm}$ a sharp band compared to the separated spiky $\mathrm{Fe}_{3} \mathrm{O}_{4} @ \mathrm{Au}$ SPs solution (Figure 7b).

\section{Conclusions}

We have demonstrated a new method for the formation of spiky nanoscale particles, which represent some of the interesting non-Platonic, non-Archimedean, non-spherical, concave shapes. The formation of these particles was accomplished using a SP self-assembly approach, in which additional negatively charged $\mathrm{Au}$ NPs were attached to the surface of previously fabricated, negatively charged smooth $\mathrm{Fe}_{3} \mathrm{O}_{4} @ \mathrm{Au}$ core-shell particles. The mechanism reveals essential differences with the interpretation of the origin of spiky or bristled morphology of nanoscale structures and is likely to be applicable to other types of nanoscale structures. It is also generic and can be applied 

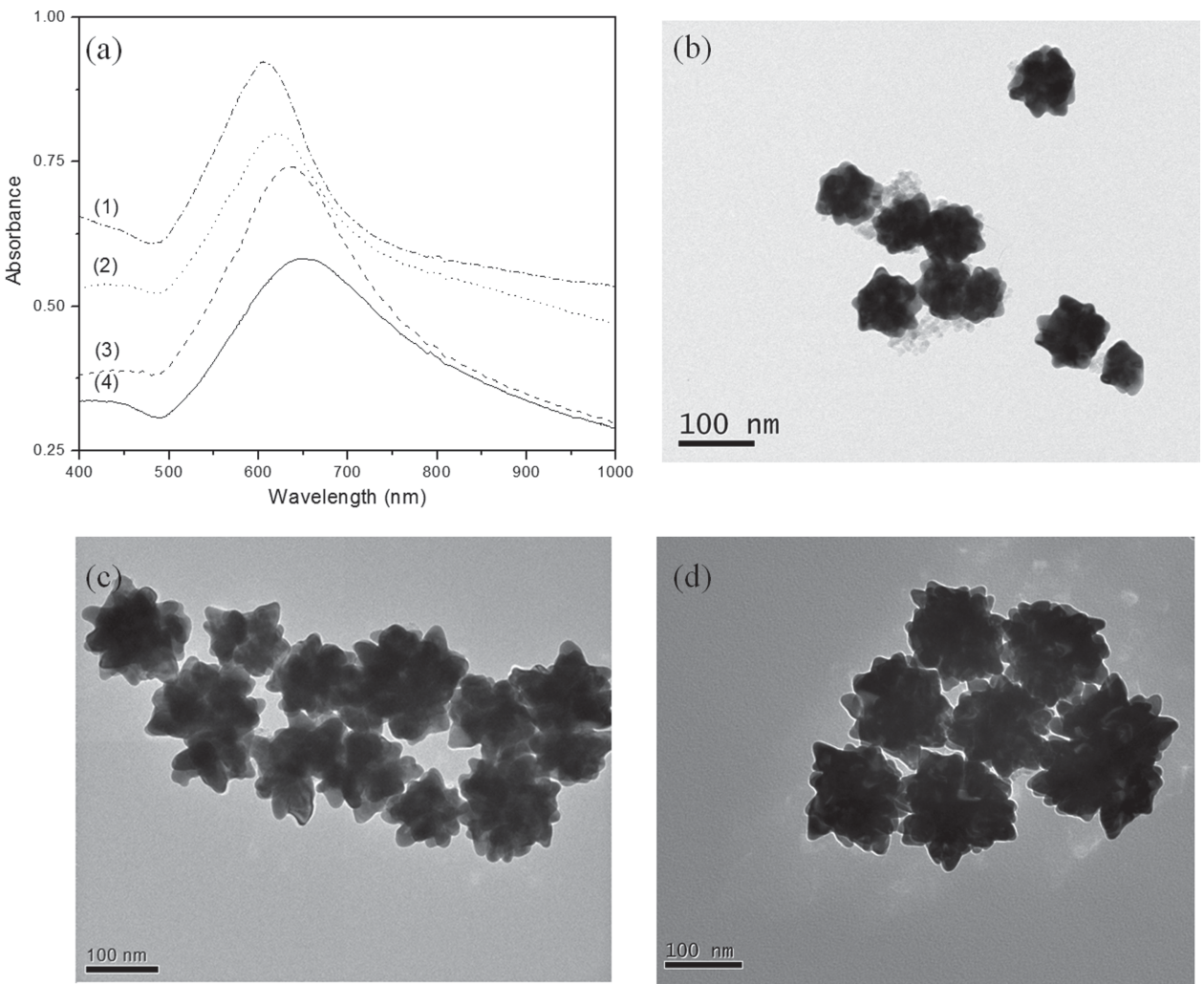

Figure 6. a) UV-visible absorption spectra of spiky SPs assembled for different amounts of hydroquinone: (1) $0.37 \mathrm{mM}$, (2) $0.72 \mathrm{mM}$, (3) $1.41 \mathrm{mM}$, and (4) $2.7 \mathrm{mM}$. The amount of seeds and sodium citrate stabilizer were fixed at 100 and $22 \mu \mathrm{L}$, respectively. b-d) TEM images of spiky SPs prepared with different volumes of hydroquinone: (b) $0.37 \mathrm{mM}$, (c) $1.41 \mathrm{mM}$, and (d) $2.7 \mathrm{mM}$. [The volume of hydroquinone: (1) $125 \mu \mathrm{L}$; (2) $250 \mu \mathrm{L}$; (3) $500 \mu \mathrm{L}$; and (4) $1000 \mu \mathrm{L}$.]

for the preparation of nano- and submicrometer particles with multiple functionalities and complex geometries.

Understanding of the SP self-assembly route makes the process of their preparation simple, fast, and easily controllable rather than empirical and fortuitous. It also makes possible to avoid utilization of polymeric compounds ${ }^{[78,79]}$ such as PVP that was considered to be essential before ${ }^{[5]}$ as well as non-aqueous solvents ${ }^{[80-82]}$ that are less desirable than aqueous dispersion of nanoscale assemblies with short easily replaceable stabilizers, especially for biological applications considering the presence of the $\mathrm{Fe}_{3} \mathrm{O}_{4}$ superparamagnetic core.
Unlike the previous cases of SP formation, we observed here a non-epitaxial merger of the Au lattices upon assembly. This process was attributed to the weak stabilization of the newly formed NPs and the presence of high-energy (200) facets. Although it is beneficial for potential applications, the lattice-tolattice connectivity of the constituent NPs limited their ability to disassemble, making thermodynamic control of their diameters difficult. To avoid this limitation, we reduced the number of constituent NPs available for assembly on the pre-made cores and demonstrated variation of diameters between 95 and $185 \mathrm{~nm}$ while maintaining the uniformity of their morphology (a)

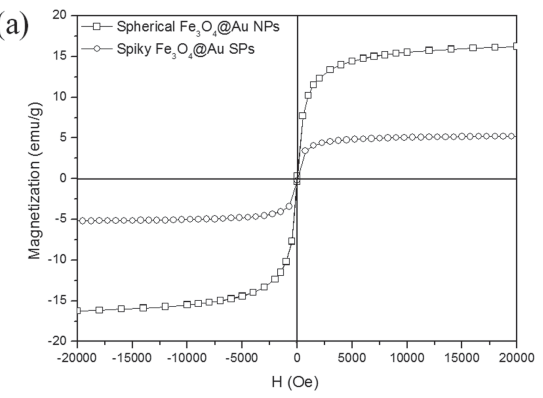

(b)

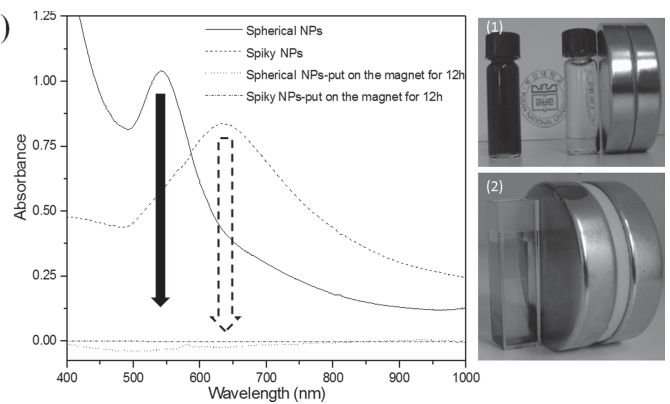

Figure 7. a) Measured magnetization moments of spherical $\mathrm{Fe}_{3} \mathrm{O}_{4} @ A$ u core-shell NPs and spiky $\mathrm{Fe}_{3} \mathrm{O}_{4} @ A$ SPs as a function of applied magnetic field at room temperature. b) UV-vis spectrum of an aqueous dispersion from $\mathrm{Fe}_{3} \mathrm{O}_{4} @ A$ u core-shell particles after being subjected to a magnetic field for $12 \mathrm{~h}$. Images on the right depict the dispersions of (1) spherical $\mathrm{Fe}_{3} \mathrm{O}_{4} @ \mathrm{Au}$ core-shell particles and (2) spiky SPs in magnetic field. 
and diameters. The reported spiky SPs can be used in multiple applications including SERS biosensing, catalysis, magnetic separation, and targeted drug delivery.

\section{Experimental Section}

Materials: Hydrogen tetrachloroaurate(III) trihydrate $\left(\mathrm{HAuCl}_{4} \cdot 3 \mathrm{H}_{2} \mathrm{O}\right.$, $99.9 \%)$, sodium citrate $\left(\mathrm{Na}_{3} \mathrm{C}_{6} \mathrm{H}_{5} \mathrm{O}_{7}\right), \mathrm{FeCl}_{3} \cdot 6 \mathrm{H}_{2} \mathrm{O}$, and hydroquinone (98\%) were supplied by Sigma-Aldrich (South Korea). $\mathrm{FeCl}_{2} \cdot 4 \mathrm{H}_{2} \mathrm{O}$ was purchased from Wako Pure Chemical Industries, Ltd. (Japan). A $28 \%$ $\mathrm{w} / \mathrm{v} \%$ ammonia solution was purchased from Duksan Pure Chemical Co., Ltd. (South Korea). Deionized water $(>18.2 \mathrm{~m} \Omega / \mathrm{cm})$ was used throughout the experimental procedure. All the chemicals were of analytical grade and used as received.

Synthesis of $\mathrm{Fe}_{3} \mathrm{O}_{4}$ Nanoparticles: $\mathrm{Fe}_{3} \mathrm{O}_{4}$ magnetic NPs were synthesized using the co-precipitation method. ${ }^{[53]}$ In a typical synthesis, $1.622 \mathrm{~g}$ of $\mathrm{FeCl}_{3} \cdot 6 \mathrm{H}_{2} \mathrm{O}$ and $0.994 \mathrm{~g}$ of $\mathrm{FeCl}_{2} \cdot 4 \mathrm{H}_{2} \mathrm{O}$ were dissolved in $40 \mathrm{~mL}$ of water under constant mechanical stirring. Then, $5 \mathrm{~mL}$ of the ammonia solution $(28 \% \mathrm{w} / \mathrm{v} \%)$ was quickly added to the reaction mixture, and the resulting solution was left undisturbed for $10 \mathrm{~min}$. Sodium citrate $(4.4 \mathrm{~g})$ was subsequently added to the reaction mixture. The reaction temperature was then raised to $90^{\circ} \mathrm{C}$, and the solution was allowed to react for 30 min under continuous stirring. The resulting black precipitate, obtained by cooling the reaction mixture to room temperature, was thoroughly rinsed with copious amounts of water several times. The precipitate was separated from the supernatant after each rinsing step using a permanent magnet. Finally, the black-colored precipitate was dried under vacuum at room temperature.

Preparation of $\mathrm{Fe}_{3} \mathrm{O}_{4} @ \mathrm{Au}$ Core-Shell Particles: Deposition of a smooth layer of gold on the $\mathrm{Fe}_{3} \mathrm{O}_{4}$ NPs was performed via reduction of $\mathrm{Au}^{3+}$ on their surface by using a modification of a previously described procedure. ${ }^{[72]}$ Briefly, a $20 \mathrm{~mL}$ aliquot of a $0.5 \mathrm{mM} \mathrm{HAuCl}$ solution was heated until it boiled and $10 \mathrm{~mL}$ of $0.136 \mu \mathrm{M}$ of the $\mathrm{Fe}_{3} \mathrm{O}_{4}$ solution was rapidly added to it under vigorous stirring. The reaction mixture gradually changed from brown to burgundy. After $10 \mathrm{~min}$ when the color of the solution stopped changing, the heater was removed while continuing the stirring action for an additional $10 \mathrm{~min}$ as the solution cooled down to room temperature. The $\mathrm{Fe}_{3} \mathrm{O}_{4} @ A u$ NPs were separated using a magnet. They were subsequently re-dispersed and centrifuged thrice at $6500 \mathrm{rpm}\left(108 \mathrm{~s}^{-1}\right)$ for $20 \mathrm{~min}$. The resulting precipitate was washed and re-suspended in deionized water. The final NP dispersion was dark purple color.

Preparation of Spiky $\mathrm{Fe}_{3} \mathrm{O}_{4} @ A u$ Supraparticles: Preparation of spiky SPs was performed via reduction of $\mathrm{Au}^{3+}$ in the presence of smooth spherical $\mathrm{Fe}_{3} \mathrm{O}_{4} @ \mathrm{Au}$ core-shell particles serving as seeds similar to the approach reported previously. ${ }^{[83,84]}$ First, a $30 \mathrm{mM}$ aqueous hydroquinone solution was prepared by dissolving $33 \mathrm{mg}$ of solid hydroquinone in $10 \mathrm{~mL}$ of deionized water. This solution must be used within 1 day. For a typical synthesis of spiky SPs, $10 \mathrm{~mL}$ of aqueous $\mathrm{HAuCl}_{4}(0.25 \mathrm{mM})$ was stirred vigorously and 100-500 $\mu \mathrm{L}$ of $\mathrm{Fe}_{3} \mathrm{O}_{4} @$ @u seeds (the smooth, spherical core-shell particles), $22 \mu \mathrm{L}$ of $1 \%$ sodium citrate solution, and $1 \mathrm{~mL}$ of the previously prepared $30 \mathrm{mM}$ hydroquinone solution were added sequentially. The resulting solution was stirred at room temperature for 30 min. The diameter and surface roughness of $\mathrm{Fe}_{3} \mathrm{O}_{4} @ A u$ NPs were tuned by altering the seeds/hydroquinone ratio, which changes the total number of Au NPs produced in the reaction system.

Optical and Microscopic Characterization: Absorbance of the $\mathrm{Fe}_{3} \mathrm{O}_{4} @$ $\mathrm{Au}$ SPs was measured by UV-vis spectroscopy (S310, SCINCO, Korea). The morphologies and sizes of the NPs were characterized using HR-TEM (JEM-3010, JEOL, Japan) and AFM (dilnnova, Veeco). The surface potentials and particle size distribution of the NPs were monitored by a zeta-sizer (Nano ZS, Malvern Instruments, Great Britain). An X-ray powder diffractometer with $\mathrm{Cu}$ Ka radiation and a $\mathrm{Ni}$ filter (D8 FOCUS $2.2 \mathrm{~kW}$, Bruker, Germany) were used to characterize the $\mathrm{Fe}_{3} \mathrm{O}_{4} @ \mathrm{Au} \mathrm{SPs}$. The data were collected at $2 \theta$ from $10^{\circ}$ to $90^{\circ}$ at a scan rate of $0.06^{\circ}$ per step and $2 \mathrm{~s}$ per point. Magnetic measurements were performed using a superconducting quantum interference device (SQUID) magnetometer (MPMS XL-7, Quantum Design, USA). ${ }^{[85]}$

\section{Supporting Information}

Supporting Information is available from the Wiley Online Library or from the author.

\section{Acknowledgments}

This study was supported by grants from the Korea Healthcare Technology R\&D Project (A110191), Ministry for Health, Welfare \& Family Affairs; the New \& Renewable Energy program of the KETEP (No. 20103020010050) funded by the Ministry of Knowledge Economy. This work also was partially supported by the Center for Solar and Thermal Energy Conversion, Energy Frontier Research Center funded by the U.S. Department of Energy, Office of Science, Office of Basic Energy Sciences under Award Number \#DE-SC0000957. We acknowledge support from the NSF under grant ECS-0601345; EFRI-BSBA 0938019 ; CBET 0933384; CBET 0932823; and CBET 1036672. The work was also partially supported by ARO MURI W911NF-12-1-0407 "Coherent Effects in Hybrid Nanostructures for Lineshape Engineering of Electromagnetic Media." H. Zhou carried out the synthesis and spectroscopic studies and drafted the manuscript. J. Kim carried out the microscopic studies. J. $\mathrm{H}$. Bahng calculated the physical binding interaction between individual Au NPs and smooth, spherical Fe3O4@Au core-shell seed NPs. N. Kotov and J. Lee conceived of the study, and participated in its design and coordination. All authors read and approved the final manuscript.

Received: July 17, 2013

Revised: August 13, 2013

Published online: October 25, 2013

[1] J. de Graaf, R. van Roij, M. Dijkstra, Phys. Rev. Lett. 2011, 107, 155501.

[2] P. F. Damasceno, M. Engel, S. C. Glotzer, Science 2012, 337, 453.

[3] U. Agarwal, F. A. Escobedo, Nat. Mater. 2011, 10, 230.

[4] Q. Wei, H. M. Song, A. P. Leonov, J. A. Hale, D. Oh, Q. K. Ong, K. Ritchie, A. Wei, J. Am. Chem. Soc. 2009, 131, 9728.

[5] N. Pazos-Pérez, S. Barbosa, L. Rodraguez-Lorenzo, P. Aldeanueva-Potel, J. Pérez-Juste, I. Pastoriza-Santos, R. A. AlvarezPuebla, L. M. Liz-Marzán, J. Phys. Chem. Lett. 2010, 1, 24.

[6] P. S. Kumar, I. Pastoriza-Santos, B. Rodriguez-González, F. J. G. de Abajo, L. Liz-Marzán, Nanotechnology 2007, 19, 015606.

[7] C. L. Nehl, H. Liao, J. H. Hafner, Nano Lett. 2006, 6, 683.

[8] H. Zhao, S. Yang, H. You, Y. Wu, B. Ding, Green Chem. 2012, 14, 3197.

[9] H. M. Song, Q. Wei, Q. K. Ong, A. Wei, ACS Nano 2010, 4, 5163.

[10] S. E. Habas, H. Lee, V. Radmilovic, G. A. Somorjai, P. Yang, Nat. Mater. 2007, 6, 692.

[11] M. J. Mulvihill, X. Y. Ling, J. Henzie, P. Yang, J. Am. Chem. Soc. 2009, 132, 268

[12] J. Lee, H. Zhou, J. Lee, J. Mater. Chem. 2011, 21, 16935.

[13] Y. Xia, Y. Xiong, B. Lim, S. E. Skrabalak, Angew. Chem. Int. Ed. 2009 $48,60$.

[14] C. Burda, X. Chen, R. Narayanan, M. A. El-Sayed, Chem. Rev. 2005, $105,1025$.

[15] A. R. Tao, S. Habas, P. Yang, Small 2008, 4, 310.

[16] J. Lee, N. A. Kotov, Nano Today 2007, 2, 48.

[17] N. Tian, Z. Y. Zhou, N. F. Yu, L. Y. Wang, S. G. Sun, J. Am. Chem. Soc. 2010, 132, 7580 . 
[18] T. Ming, W. Feng, Q. Tang, F. Wang, L. Sun, J. Wang, C. Yan, J. Am. Chem. Soc. 2009, 131, 16350.

[19] Z. Y. Zhou, Z. Z. Huang, D. J. Chen, Q. Wang, N. Tian, S. G. Sun, Angew. Chem. 2010, 122, 421.

[20] Y. Ma, Q. Kuang, Z. Jiang, Z. Xie, R. Huang, L. Zheng, Angew. Chem. Int. Ed. 2008, 47, 8901.

[21] D. Y. Kim, S. H. Im, O. O. Park, Cryst. Growth. Des. 2010, 10, 3321.

[22] J. Zhang, M. R. Langille, M. L. Personick, K. Zhang, S. Li, C. A. Mirkin, J. Am. Chem. Soc. 2010, 132, 14012.

[23] C. L. Lu, K. S. Prasad, H. L. Wu, J. A. A. Ho, M. H. Huang, J. Am. Chem. Soc. 2010, 132, 14546.

[24] Y. Yu, Q. Zhang, B. Liu, J. Y. Lee, J. Am. Chem. Soc. 2010, 132, 18258.

[25] F. Wang, C. Li, L. D. Sun, H. Wu, T. Ming, J. Wang, J. C. Yu, C. H. Yan, J. Am. Chem. Soc. 2010, 133, 1106.

[26] H. Y. Wu, M. Liu, M. H. Huang, J. Phys. Chem. B 2006, 110, 19291.

[27] S. Srivastava, A. Santos, K. Critchley, K. S. Kim, P. Podsiadlo, K. Sun, J. Lee, C. Xu, G. D. Lilly, S. C. Glotzer, N. A. Kotov, Science 2010, 327,1355

[28] N. A. Kotov, Science 2010, 330, 188.

[29] N. Tian, Z. Y. Zhou, S. G. Sun, J. Phys. Chem. C 2008, 112, 19801.

[30] N. Tian, Z. Y. Zhou, S. G. Sun, L. Cui, B. Ren, Z. Q. Tian, Chem. Commun. 2006, 4090

[31] Y. Wang, Z. Tang, X. Liang, L. M. Liz-Marzan, N. A. Kotov, Nano Lett. 2004, 4, 225.

[32] P. Aldeanueva-Potel, E. Carbó-Argibay, N. Pazos-Pérez, S. Barbosa, I. Pastoriza-Santos, R. Varez-Pueblá, L. Liz-Marzán, ChemPhysChem 2012, 13, 2561

[33] H. M. Chen, R. S. Liu, D. P. Tsai, Cryst. Growth. Des. 2009, 9, 2079.

[34] W. Du, X. Qian, X. Niu, Q. Gong, Cryst. Growth. Des. 2007, 7, 2733.

[35] N. G. Bastús, J. Comenge, V. Puntes, Langmuir 2011, 27, 11098.

[36] A. Guerrero-Martínez, S. Barbosa, I. Pastoriza-Santos, L. M. Liz-Marzán, Curr. Opin. Colloid Interface Sci. 2011, 16, 118.

[37] A. Querejeta-Fernández, J. C. Hernández-Garrido, H. Yang, Y. Zhou, A. Varela, M. Parras, J. Calvino-Gámez, J. M. González-Calbet, P. F. Green, N. A. Kotov, ACS Nano 2012, 6, 3800.

[38] Z. Tang, Z. Zhang, Y. Wang, S. C. Glotzer, N. A. Kotov, Science 2006, 314,274

[39] Y. Xia, T. D. Nguyen, M. Yang, B. Lee, A. Santos, P. Podsiadlo, Z. Tang, S. C. Glotzer, N. A. Kotov, Nat. Nanotechnol. 2011, 6, 580.

[40] E. C. Dreaden, A. M. Alkilany, X. Huang, C. J. Murphy, M. A. El-Sayed, Chem. Soc. Rev. 2012, 41, 2740.

[41] W. Chen, N. Xu, L. Xu, L. Wang, Z. Li, W. Ma, Y. Zhu, C. Xu, N. A. Kotov, Macromol. Rapid Commun. 2010, 31, 228.

[42] J. H. Jung, J. H. Lee, S. Shinkai, Chem. Soc. Rev. 2011, 40, 4464.

[43] D. Yoo, J. H. Lee, T. H. Shin, J. Cheon, Acc. Chem. Res. 2011, 44, 863.

[44] C. Tassa, S. Y. Shaw, R. Weissleder, Acc. Chem. Res. 2011, 44, 842.

[45] B. Godin, E. Tasciotti, X. Liu, R. E. Serda, M. Ferrari, Acc. Chem. Res. 2011, 44, 979.

[46] G. K. Kouassi, J. Irudayaraj, Anal. Chem. 2006, 78, 3234.

[47] I. Robinson, L. D. Tung, S. Maenosono, C. Wälti, N. T. K. Thanh, Nanoscale 2010, 2, 2624.

[48] M. Riepl, M. Östblom, I. Lundström, S. C. T. Svensson, A. W. D. van der Gon, M. Schäferling, B. Liedberg, Langmuir 2005, $21,1042$.

[49] L. C. Cheng, J. H. Huang, H. M. Chen, T. C. Lai, K. Y. Yang, R. S. Liu, M. Hsiao, C. H. Chen, L. J. Her, D. P. Tsai, J. Mater. Chem. 2012, 22, 2244.

[50] K. C.-F. Leung, S. Xuan, X. Zhu, D. Wang, C. P. Chak, S. F. Lee, W. K. W. Ho, B. C. T. Chung, Chem. Soc. Rev. 2012, 41, 1911.

[51] G. Maiorano, L. Rizzello, M. A. Malvindi, S. S. Shankar, L. Martiradonna, A. Falqui, R. Cingolani, P. P. Pompa, Nanoscale 2011, 3, 2227.
[52] J. J. Storhoff, R. Elghanian, R. C. Mucic, C. A. Mirkin, R. L. Letsinger, J. Am. Chem. Soc. 1998, 120, 1959.

[53] H. Zhou, J. Lee, T. J. Park, S. J. Lee, J. Y. Park, J. Lee, Sens. Actuators B-Chem. 2012, 163, 224.

[54] A. Agarwal, X. Shao, J. R. Rajian, H. Zhang, D. L. Chamberland, N. A. Kotov, X. Wang, J. Biomed. Opt. 2011, 16, 051307.

[55] E. Nalbant Esenturk, A. R. Hight Walker, J. Raman Spectrosc. 2009, $40,86$.

[56] L. Brus, Acc. Chem. Res. 2008, 41, 1742.

[57] R. Narayanan, M. A. El-Sayed, J. Phys. Chem. B 2005, 109, 12663.

[58] S. D. Perrault, W. C. W. Chan, J. Am. Chem. Soc. 2009, 131, 17042.

[59] C. S. Levin, C. Hofmann, T. A. Ali, A. T. Kelly, E. Morosan, P. Nordlander, K. H. Whitmire, N. J. Halas, ACS Nano 2009, 3, 1379.

[60] P. Sharma, V. Bhalla, V. Dravid, G. Shekhawat, E. S. Prasad, C. R. Suri, Sci. Rep. 2012, 2, 877.

[61] J. Gallo, I. García, D. Padro, B. Arnáiz, S. Penadés, J. Mater. Chem. 2010, 20, 10010 .

[62] S. T. Gentry, S. J. Fredericks, R. Krchnavek, Langmuir 2009, 25, 2613

[63] A. J. Bard, H. Zhou, S. J. Kwon, Isr. J. Chem. 2010, 50, 267.

[64] X. Xiao, A. J. Bard, J. Am. Chem. Soc. 2007, 129, 9610.

[65] E. Gachard, H. Remita, J. Khatouri, B. Keita, L. Nadjo, J. Belloni, New J. Chem. 1998, 22, 1257.

[66] A. Mechler, A. A. Torriero, A. Nafady, C. Y. Lee, A. M. Bond A. P. O' Mullane, S. Bhargava, Colloid Surf. A-Physicochem.Eng. Asp. 2010, 370, 35

[67] J. N. Israelachvili, Intermolecular and Surface Forces: Revised, 3rd edition, Academic Press, San Diego 2011,

[68] J. Goodwin, Colloids and Interfaces with Surfactants and Polymers, Wiley, West Sussex 2009.

[69] H. C. Chang, G. Yossifon, E. A. Demekhin, Annu. Rev. Fluid Mech. 2012, 44, 401

[70] G. Frens, Nat. Phys. Sci. 1973, 241, 20

[71] C. Huang, J. Jiang, C. Muangphat, X. Sun, Y. Hao, Nanoscale Res Lett 2011, 6, 1 .

[72] J. Li, J. Wu, X. Zhang, Y. Liu, D. Zhou, H. Sun, H. Zhang, B. Yang, J. Phys. Chem. C 2011, 115, 3630

[73] K. R. Brown, D. G. Walter, M. J. Natan, Chem. Mater. 2000, 12, 306.

[74] Z. Tang, N. A. Kotov, M. Giersig, Science 2002, 297, 237.

[75] E. Prodan, C. Radloff, N. J. Halas, P. Nordlander, Science 2003, 302, 419.

[76] N. J. Halas, S. Lal, S. Link, W. S. Chang, D. Natelson, J. H. Hafner, P. Nordlander, Adv. Mater. 2012, 24, 4842.

[77] W. C. Huang, P. J. Tsai, Y. C. Chen, Small 2009, 5, 51.

[78] J. Shan, H. Tenhu, Chem. Commun. 2007, 0, 4580.

[79] S. Xing, L. H. Tan, M. Yang, M. Pan, Y. Lv, Q. Tang, Y. Yang, H. Chen, J. Mater. Chem. 2009, 19, 3286.

[80] V. Mazumder, M. Chi, K. L. More, S. Sun, Angew. Chem. 2010, 122, 9558.

[81] Y. Jin, C. Jia, S. W. Huang, M. O’Donnell, X. Gao, Nat. Commun. 2010, 1, 41.

[82] R. Hao, R. Xing, Z. Xu, Y. Hou, S. Gao, S. Sun, Adv. Mater. 2010, 22, 2729.

[83] K. C. Grabar, R. G. Freeman, M. B. Hommer, M. J. Natan, Anal. Chem. 1995, 67, 735.

[84] H. Zhou, J. Dong, V. K. Deo, E. Y. Park, J. Lee, Sens. Actuators BChem. 2012, 178, 192.

[85] W. Lianyan, J. Luo, Q. Fan, M. Suzuki, I. S. Suzuki, M. H. Engelhard, Y. Lin, N. Kim, J. Q. Wang, C. J. Zhong, J. Phys. Chem. B 2005, 109, 21593 